\title{
ORTHODONTIC AND SURGICAL TREATMENT OF A PATIENT WITH AN IMPACTED UPPER CENTRAL INCISOR WITH DILACERATIONS - SYSTEMATIC REVIEW OF THE LITERATURE WITH PRESENTATION OF A CASE
}

\author{
Magdalena Rudnik ${ }^{1}$, Tomasz Kaczmarzyk², Anna Bednarczyk ${ }^{2}$, Bartłomiej W. Loster ${ }^{1}$ \\ 'Department of Orthodontics, Dental Institute, Faculty of Medicine, Jagiellonian University Medical College, Cracow, Poland \\ ${ }^{2}$ Department of Oral Surgery, Dental Institute, Faculty of Medicine, Jagiellonian University Medical College, Cracow, Poland
}

\begin{abstract}
INTRODUCTION: Impacted upper central incisors are a big aesthetic, developmental and social problem for patients. One of the causes of tooth eruption is dilaceration, which is the angulation of the tooth root in relation to its crown. The prognosis regarding the possibility of introducing teeth with dilaceration to the dental arch is uncertain and is characterized by a large number of failures. The aim of the study was to conduct a systematic review of the literature discussing the subject of impacted upper central incisors with confirmed dilaceration and illustrate this problem with the presentation of our own clinical case.

Овjectives: The aim of the study was to conduct a systematic review of the literature discussing the subject of impacted maxillary central incisors with confirmed dilaceration and to illustrate this problem with the presentation of a clinical case.

MATERial AND METhoDs: A systematic review of the literature was conducted by searching the medical databases of PubMed and Scopus. The search was carried out by entering the following keywords: dilaceration, impacted tooth, impacted maxillary central incisors. Non-systematic reviews of the literature were excluded from the analysis.

RESULTS: The result of searching the databases was a total of 706 articles. Twenty-nine articles corresponding to the objectives of the study were included in the analysis. Among them were original papers, meta-analyses and case reports. The problem of impacted upper central incisors with the diagnosed dilaceration is illustrated by the description of the orthodontic and surgical treatment of the case.

Conclusions: Patients with diagnosed impacted tooth with dilaceration require detailed diagnostics to plan orthodontic treatment. The implementation of a comprehensive orthodontic and surgical treatment at an early stage of tooth development gives the best prognosis to introduce a tooth with dilaceration to the dental arch.
\end{abstract}

KEY WORDS: dilaceration, impacted tooth, impacted maxillary central incisors.

J Stoma 2018; 71, 3: 288-301

DOI: https://doi.org/10.5114/jos.2018.80642

\section{JOURNAL OF STOMATOLOGY CZASOPISMO STOMATOLOGICZNE}

ADDRESS FOR CORRESPONDENCE: Bartłomiej W. Loster,

Department of Orthodontics, Dental Institute, Faculty of Medicine, Jagiellonian University Medical College, 4 Montelupich St., 31-155 Kraków, Poland, phone/fax: +48 1242454 02, e-mail: bw.loster@uj.edu.pl 


\section{INTRODUCTION}

Impacted upper central incisors, manifested by their lack in the dental arch or the presence of a deciduous predecessor, constitute a big aesthetic, developmental and psychological problem. For this reason, they are diagnosed early, which allows for rapid intervention. In the study conducted by Tan [1] among children and adolescents, the incidence of impacted incisors was $2.0 \%$, of which $70.6 \%$ of cases concerned the upper medial permanent incisors. Reasons for retention of permanent teeth include lack of space in the arch [2], the presence of supernumerary teeth [2-5], odontogenic tumor or cyst $[2,5]$, impacted deciduous teeth, tissue scar created as a result of early tooth extraction, trauma to the deciduous anterior teeth [6] and tooth development disorders such as dilacerations $[1,2,4]$.

Dilaceration is the phenomenon of bending the root of the tooth in relation to its crown, which is usually observed among the third molars of the mandible [7-10]. Studies on the prevalence of dilaceration in individual dental groups showed the occurrence of this disorder within the central upper incisors within the range of $0.2-1.2 \%[7,9,11,12]$. In studies on the prevalence of dental anomalies, apart from taurodontism, impacted teeth, hypodontia and supernumerary teeth, dilaceration was one of the most common dental defects and constituted between $1.4 \%$ and $46.71 \%$ of all dental anomalies [13-22]. Dilaceration was more frequently observed in maxillary teeth than in mandibular teeth $[9,11,23]$. In two studies, dilaceration occurred to the same extent in maxilla and in the mandible $[10,12]$. The root curvature may be anterio-lingual or mesial-distal [24]. Silva [11] defines dilaceration as more than 20 degrees crown-root curvature. Hamasha [7], Malcić [9], Udoye [23] and Nabavizadeh [12] in their studies referred to dilaceration when the crown-root angulation exceeded $90 \%$ in the mesial or distal direction. The dilaceration in the vestibular or palatal direction was determined on the basis of the "bull's-eye" symptom - the deviating root portion forms a round radiopaque area with a dark central area permeable to X-rays, which is the root canal [24]. Dilaceration usually occurs unilaterally. Clinically, the dilaceration of a tooth may result in the retention of a permanent tooth $[2,4]$, presence of a persistent deciduous tooth in the mouth, or fenestration of the cortical atrium plate [25-27] or cortical palatal plate [6, 24]. It is formed at the stage of forming tooth buds [28]. The position of the permanent teeth buds near to and at a very short distance from the tips of the deciduous teeth causes that the injuries of the deciduous teeth are transferred to the developing permanent teeth. Depending on the stage of forming a permanent tooth bud, the trauma to the deciduous tooth causes various developmental disorders from mineralization disorders to completely abnormal development of the germ - odon- toma-like malformation. If the injury takes place during the formation of the crown, the formation of the enamel will be disturbed, which results in the incorrect shape of the permanent tooth. If the injury occurs after forming the crown of a permanent tooth, it may lead to inhibition of the process of tooth root formation or its formation at a certain angle to the traumatic dislocated crown and as a result of the formation of the crownroot angulation [26]. The mechanism of post-traumatic dilaceration is the rotation of the tooth's bud due to the trauma of the deciduous tooth. The crown and root portion of the permanent tooth formed at the time of the injury will be rotated according to the direction of force given by the intruded deciduous tooth. The subsequent development of the root follows the direction from before the injury, causing a deviation from the long axis of the tooth. The root growth potential of a retained tooth with dilaceration is smaller than that of a tooth that is properly exfoliated, which leads to shortening of its length [29]. Dilaceration of the tooth can occur on each of its sections, within the crown, the cemento-enamel junction and the root $[6,24,30]$. Studies conducted by Stewart [5] on dilacerated teeth showed that in only some patients it was formed as a result of trauma to the deciduous teeth. According to Stewart, dilaceration in $22 \%$ of cases arises as a result of injury, $71 \%$ arise due to the ectopic location of tooth buds and $7 \%$ are associated with the presence of supernumerary teeth and cysts [5]. There is no agreement among researchers regarding the correlation of the occurrence of dilaceration with trauma within the incisors. Udoye [23] does not correlate trauma with dilaceration, whereas Tan [1] found a statistically significant relationship between these two variables. One of the arguments excluding only the traumatic etiology of dilaceration is the fact that it usually concerns a single tooth, while the injury of the deciduous teeth should also disturb the development of neighboring permanent tooth buds [6]. These observations have led to the conclusion that dilaceration is not only a derivative of deciduous teeth injuries and the creation of a theory about idiopathic tooth development disorder leading to dilaceration. Other possible causes of dilaceration are lack of space for the developing tooth, presence of tumors, ankylosis of the deciduous teeth, lack of resorption of the roots of the deciduous teeth [24], and advanced inflammation of pulp of the deciduous teeth [6].

\section{OBJECTIVES}

The aim of the study was to conduct a systematic review of the literature discussing the subject of impacted maxillary central incisors with confirmed dilaceration and to illustrate this problem with the presentation of a clinical case. 


\begin{tabular}{|c|c|c|c|c|c|}
\hline & 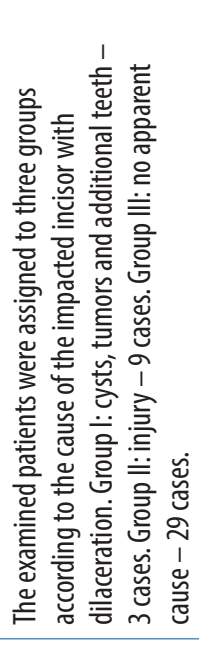 & 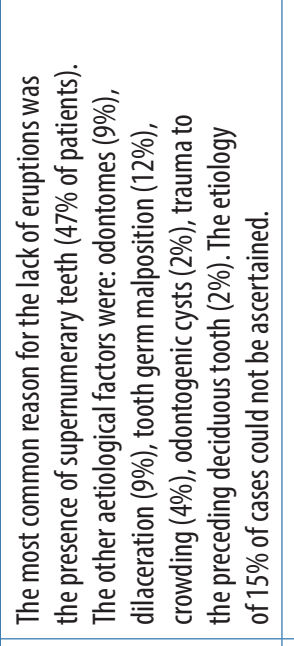 & 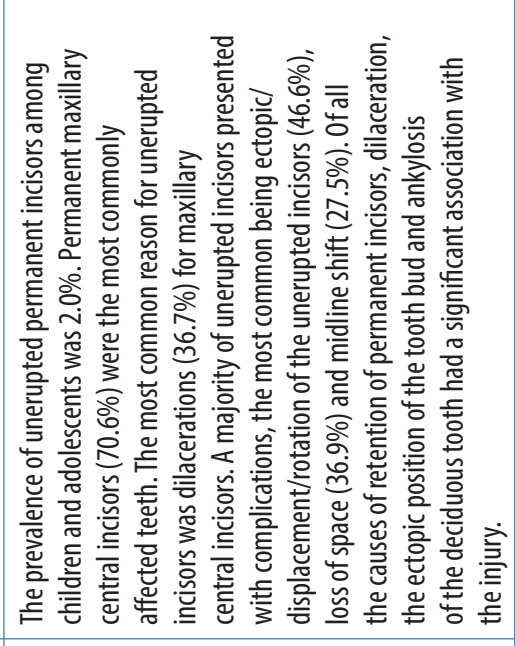 & 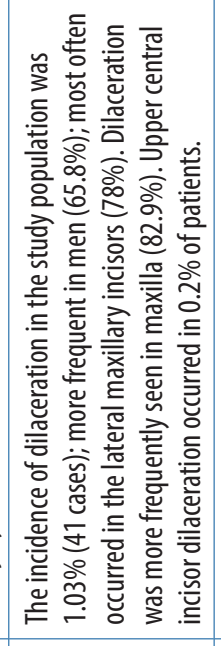 & 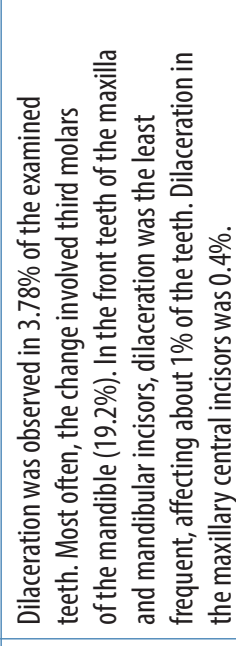 \\
\hline & 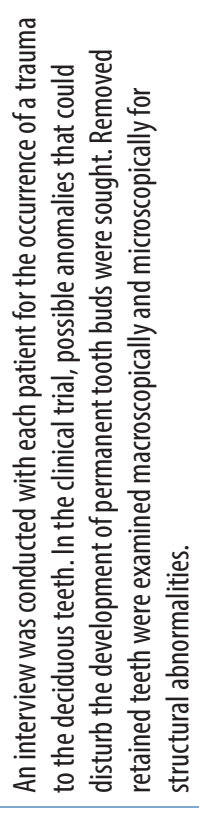 & 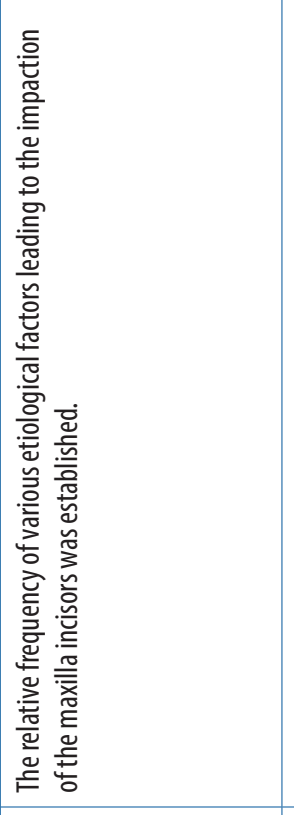 & 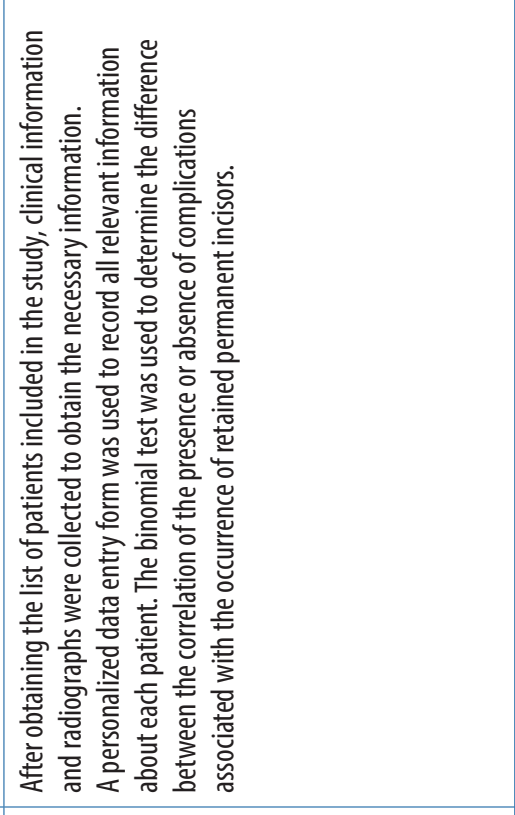 & 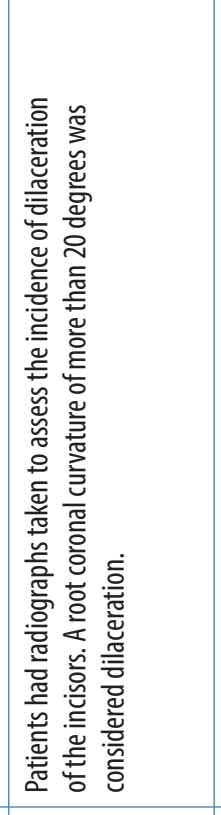 & 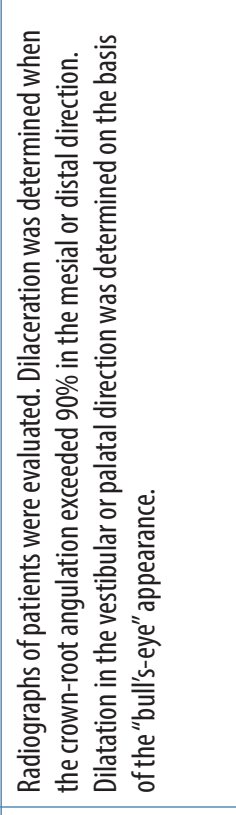 \\
\hline & 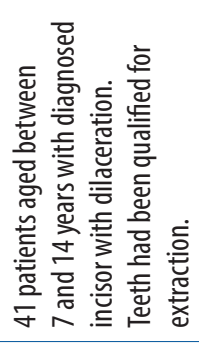 & 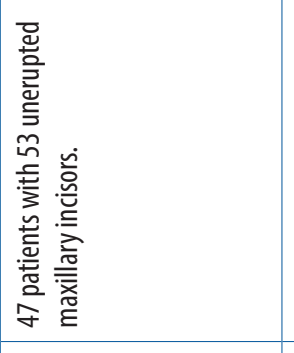 & 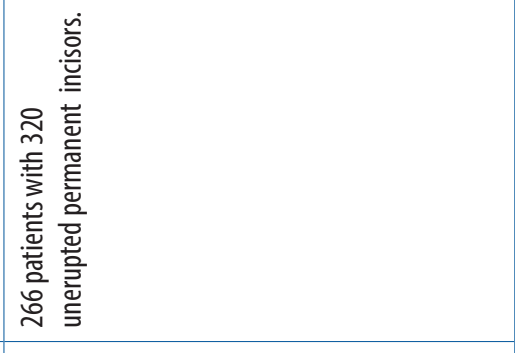 & 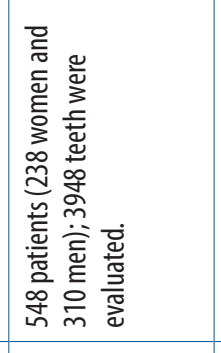 & 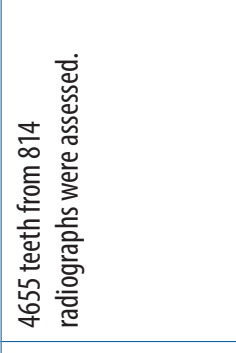 \\
\hline & 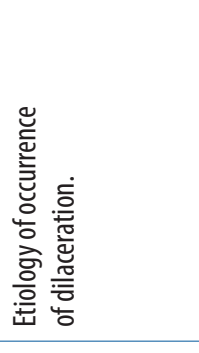 & 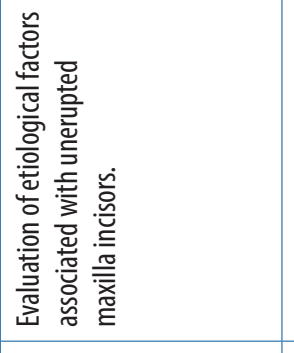 & 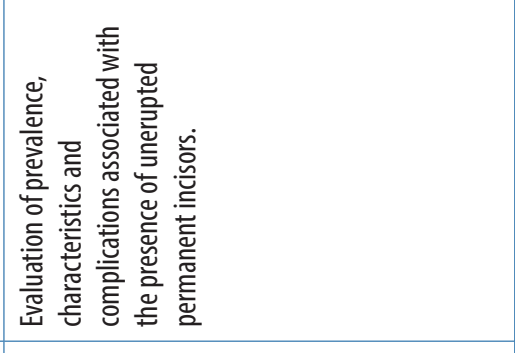 & 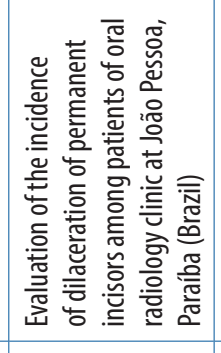 & 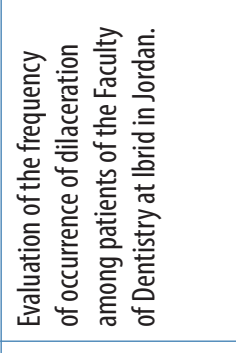 \\
\hline & & 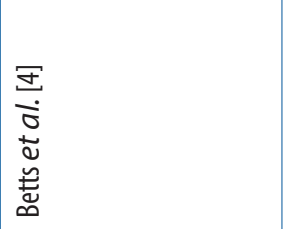 & 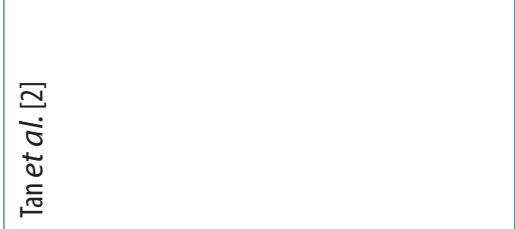 & 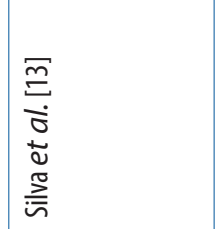 & 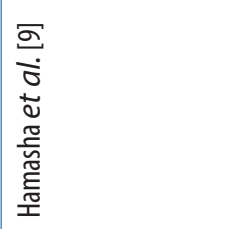 \\
\hline
\end{tabular}




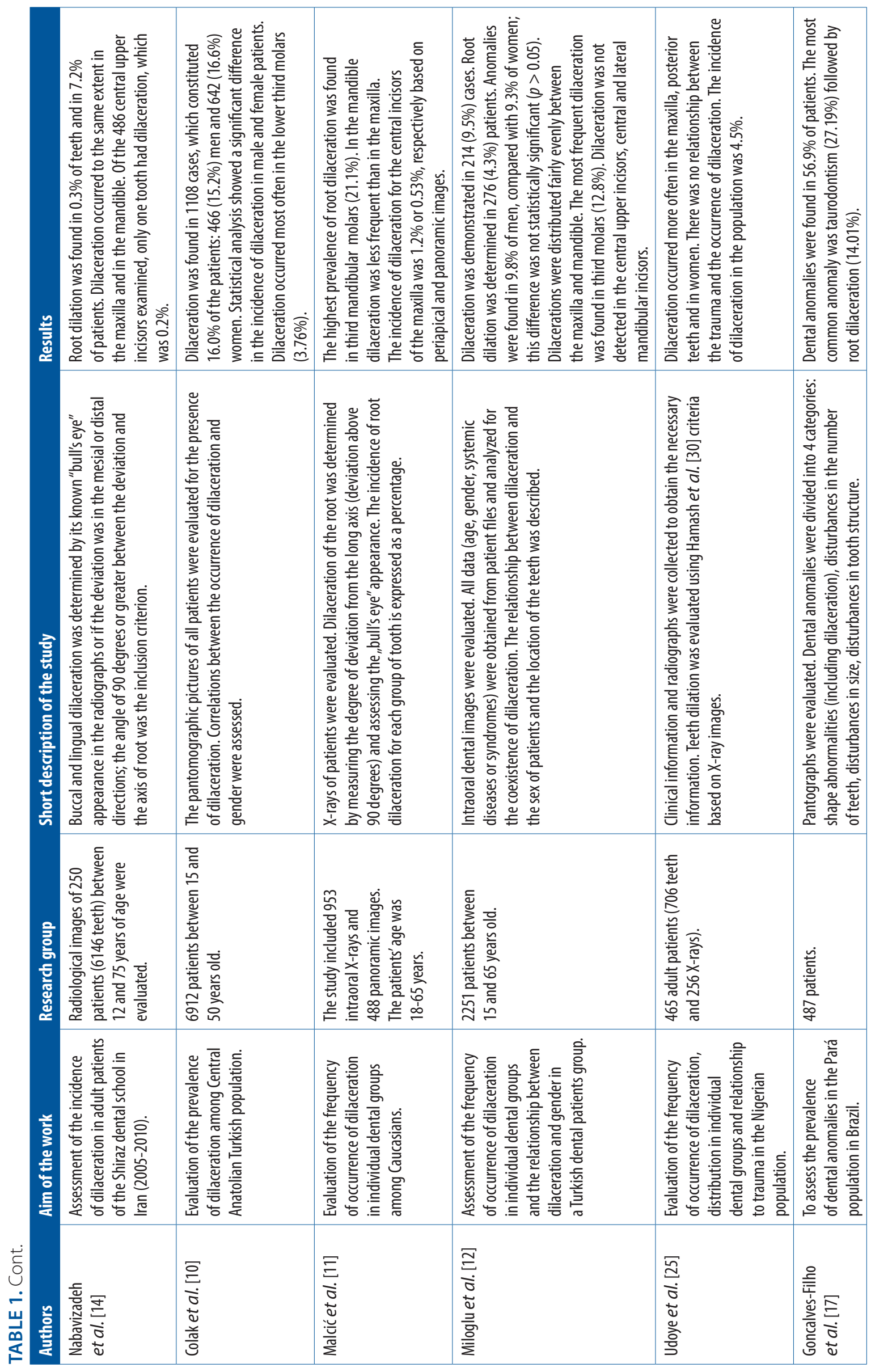




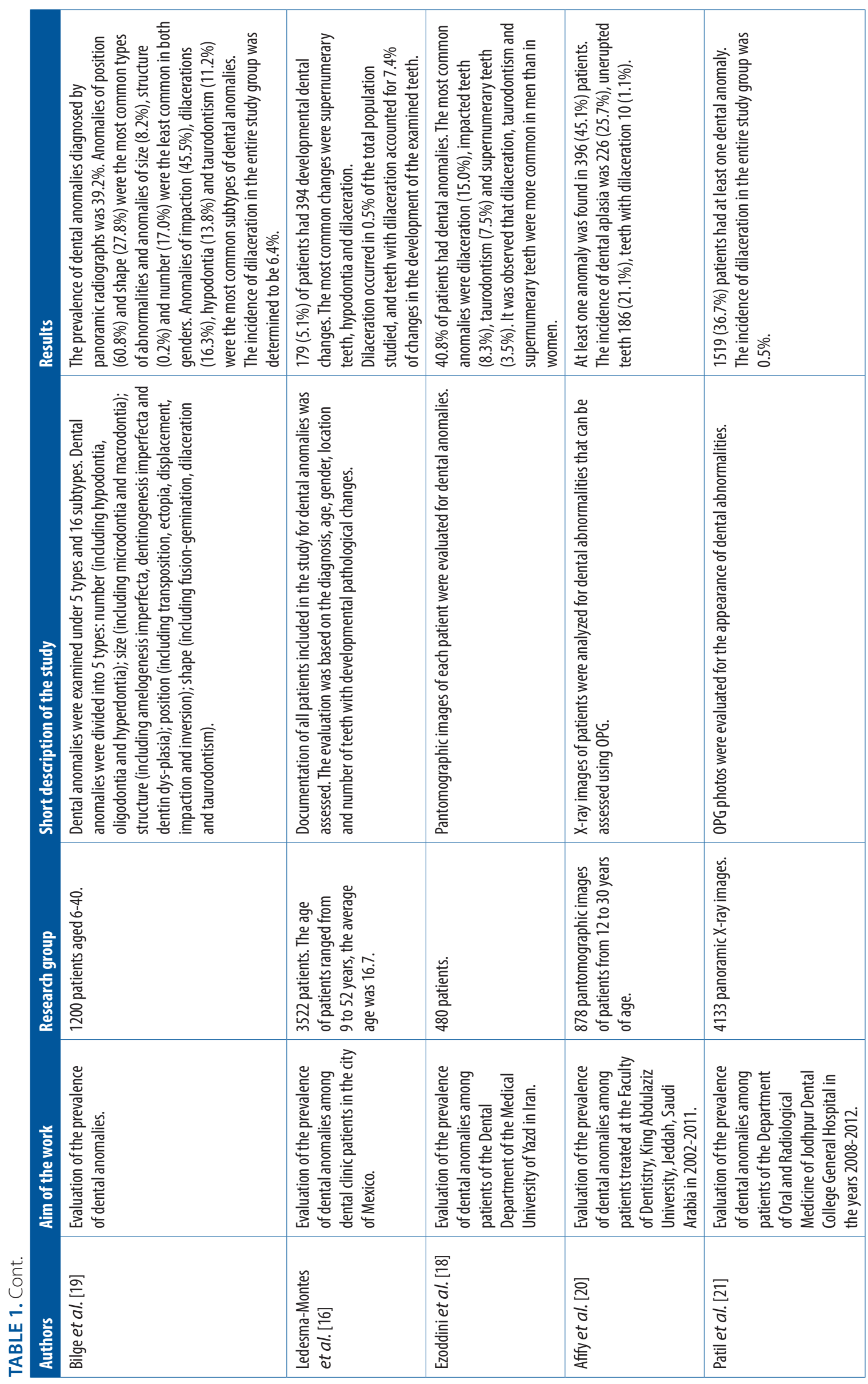




\begin{tabular}{|c|c|c|c|c|c|c|c|}
\hline & 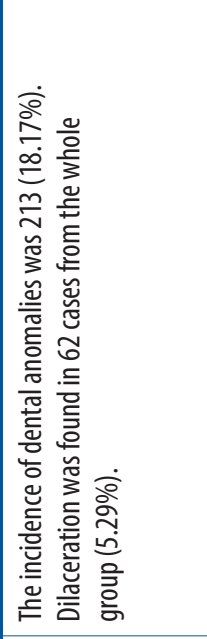 & 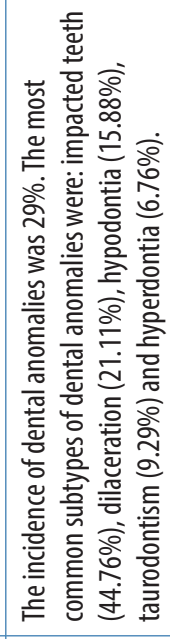 & 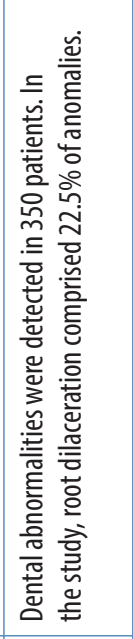 & 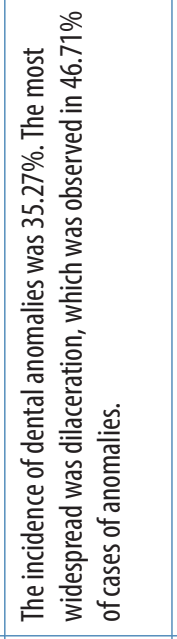 & 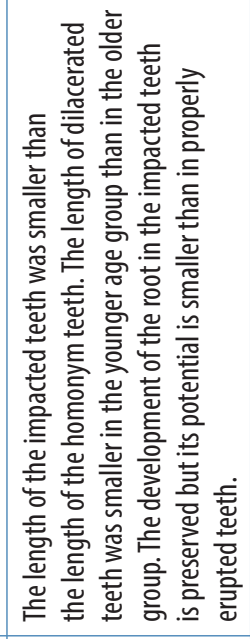 & 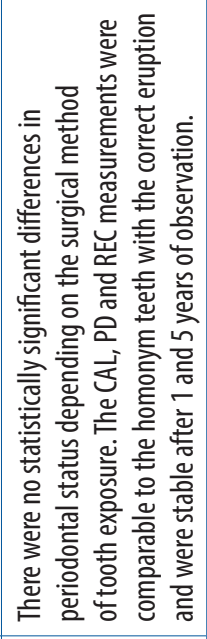 & 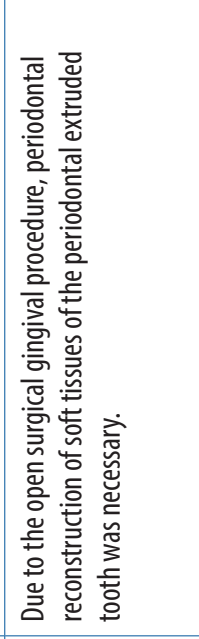 \\
\hline & 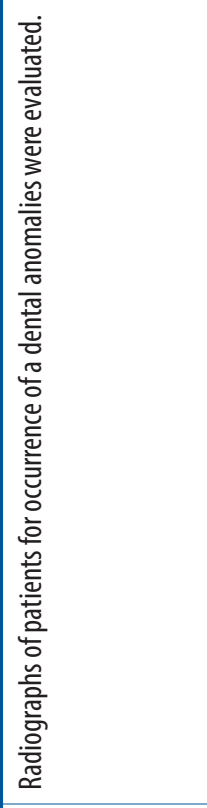 & 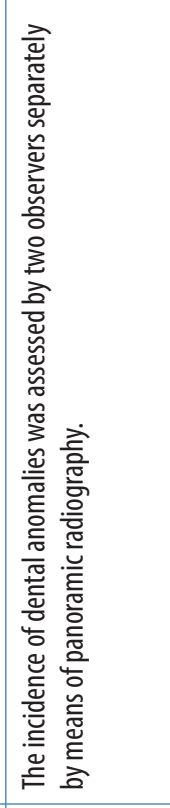 & 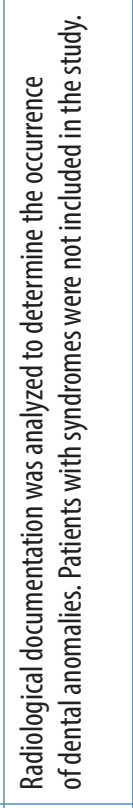 & 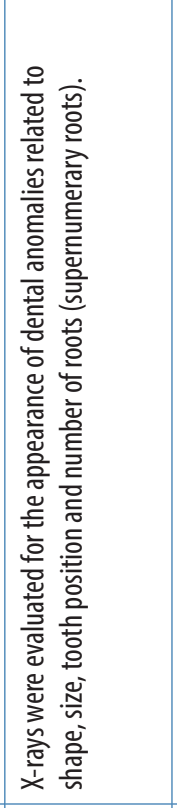 & 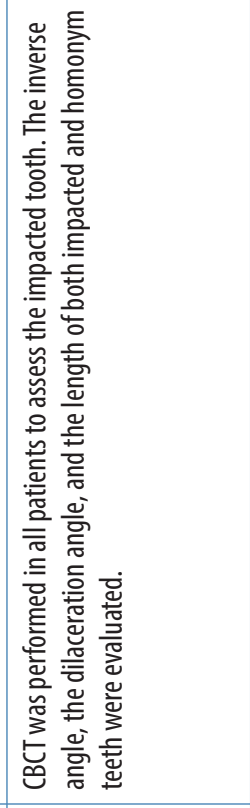 & 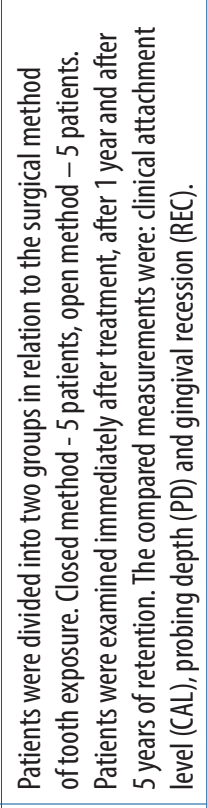 & 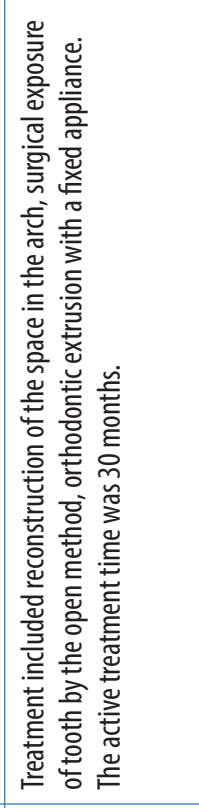 \\
\hline & 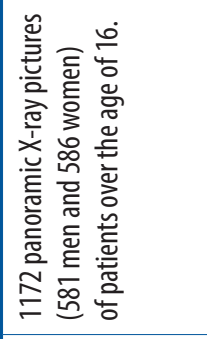 & 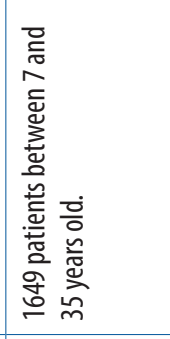 & 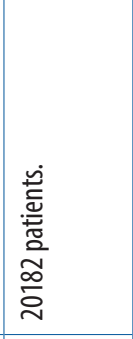 & 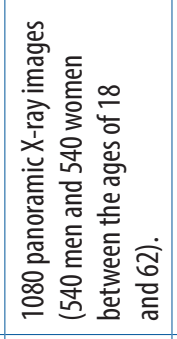 & 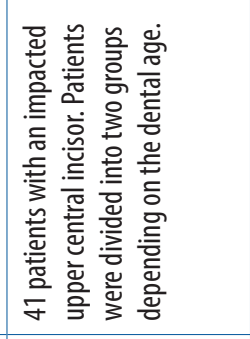 & 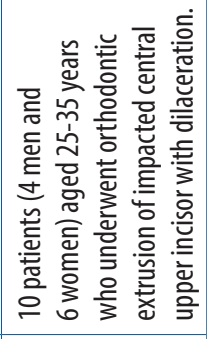 & 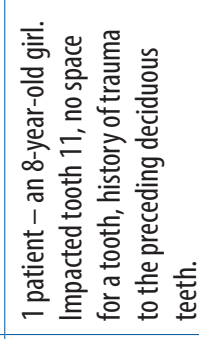 \\
\hline & 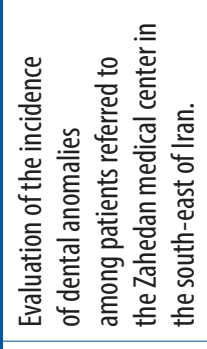 & 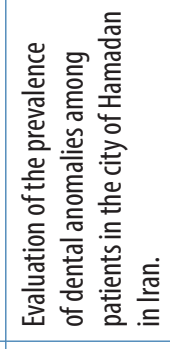 & 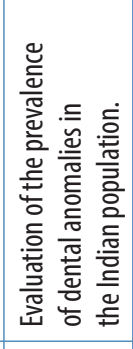 & 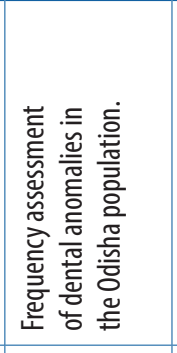 & 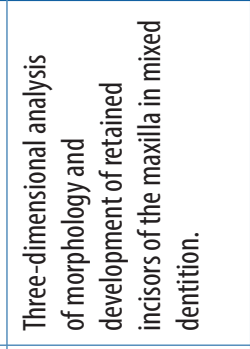 & 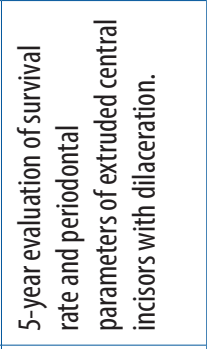 & 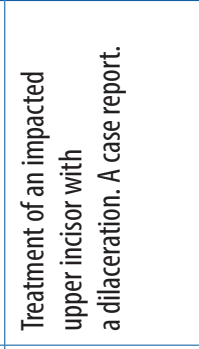 \\
\hline & 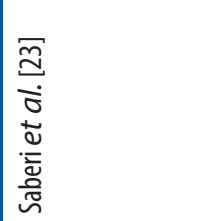 & 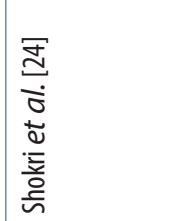 & 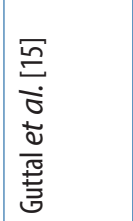 & 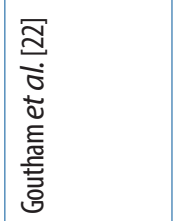 & 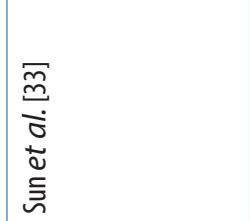 & 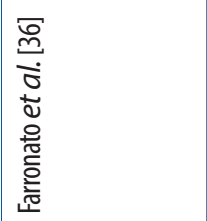 & 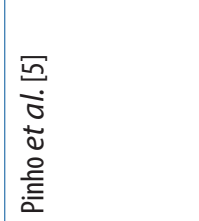 \\
\hline
\end{tabular}




\begin{tabular}{|c|c|c|c|c|c|c|}
\hline & 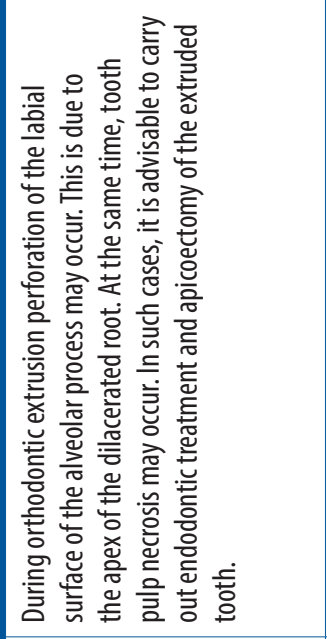 & 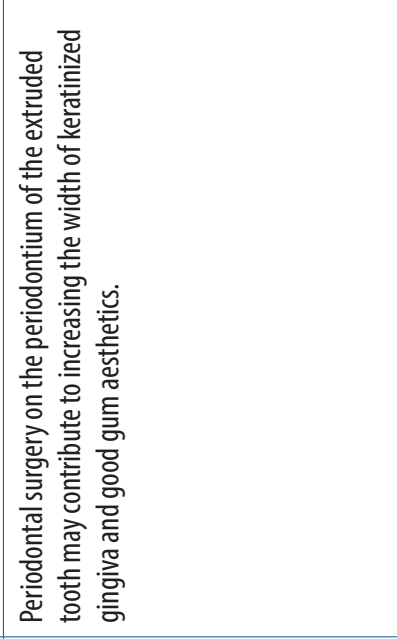 & 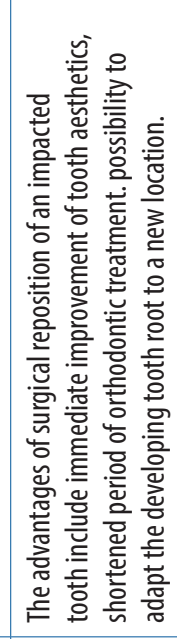 & 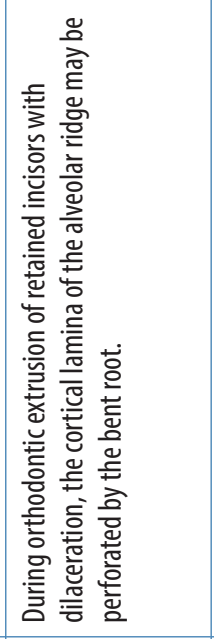 & 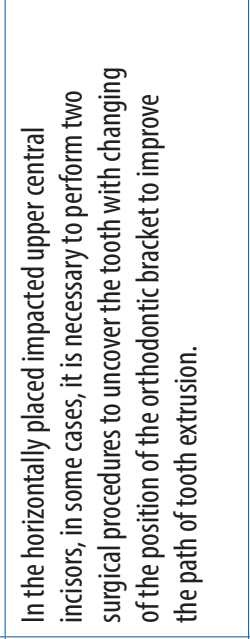 & 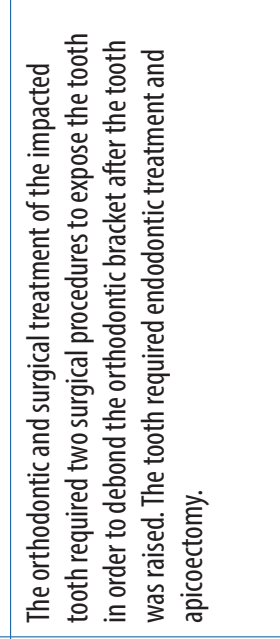 \\
\hline & 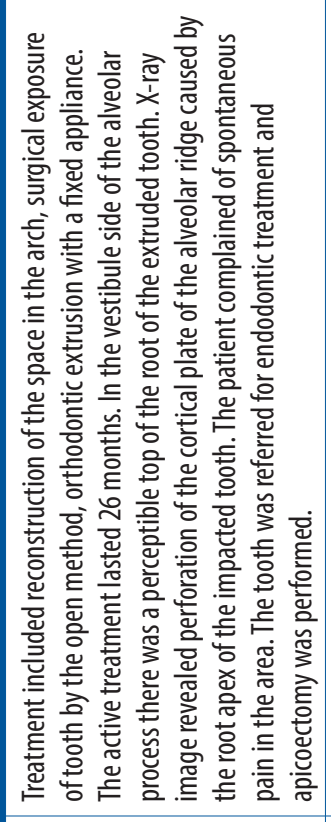 & 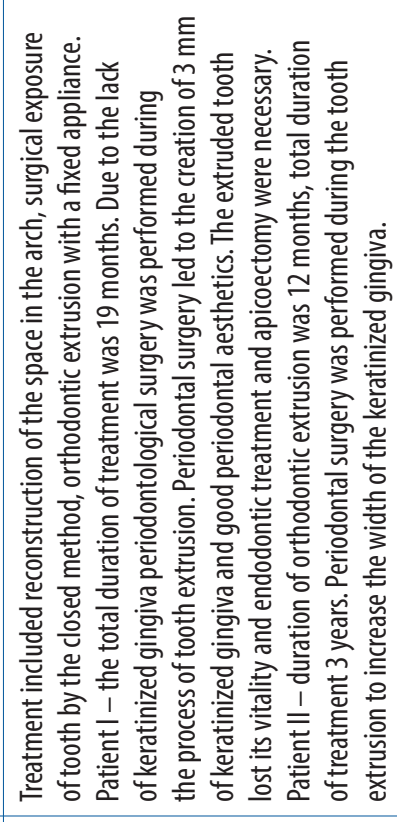 & 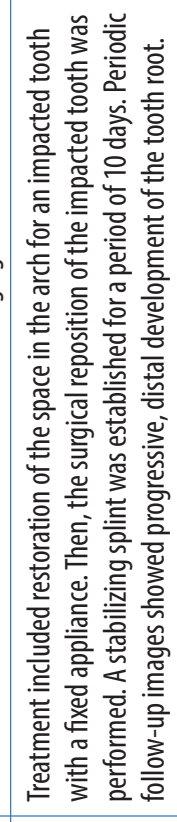 & 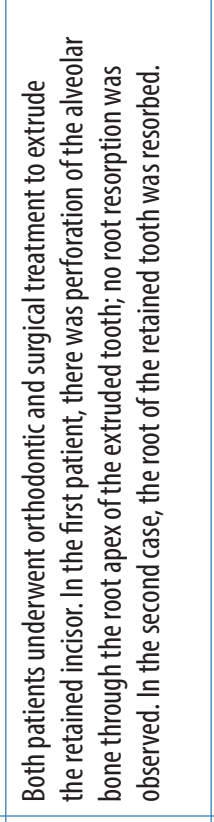 & 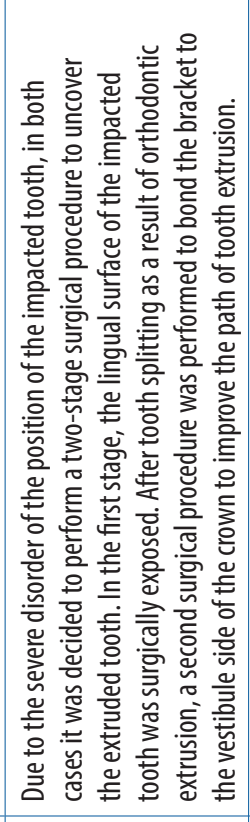 & 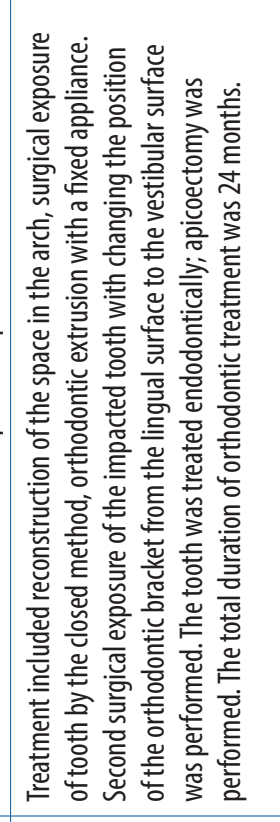 \\
\hline & 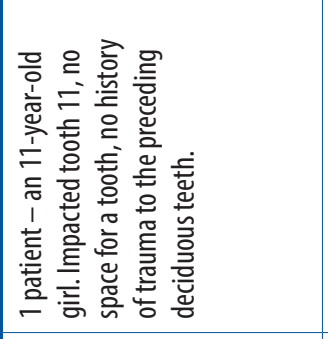 & 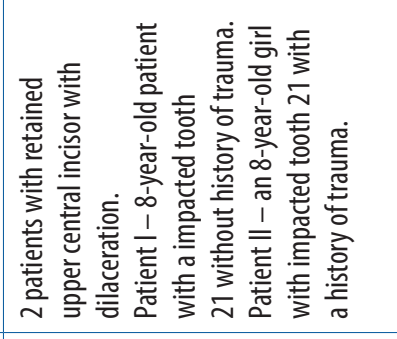 & 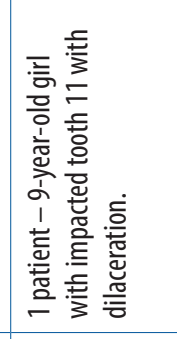 & 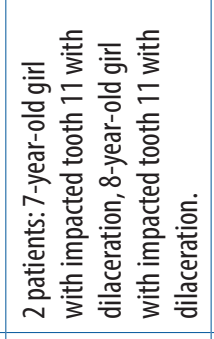 & 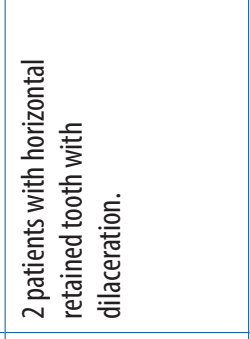 & 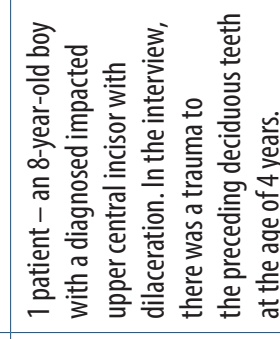 \\
\hline & 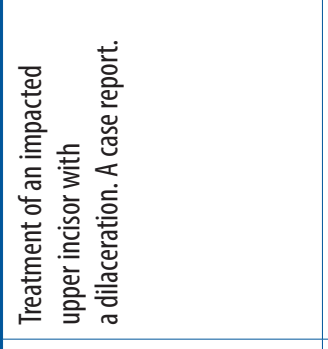 & 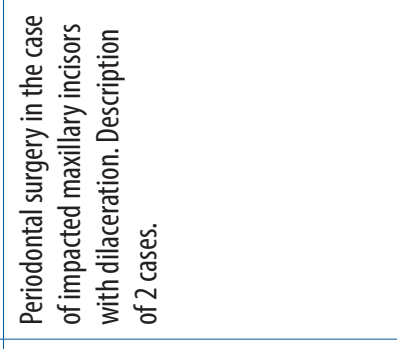 & 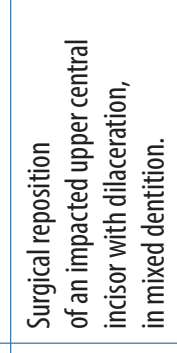 & 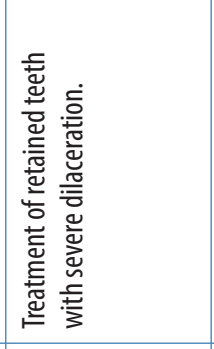 & 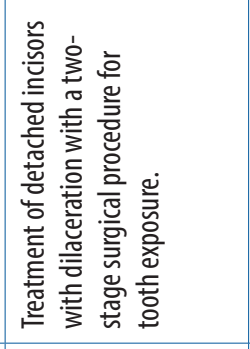 & 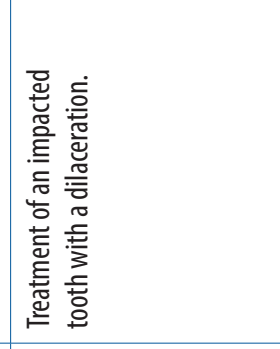 \\
\hline & 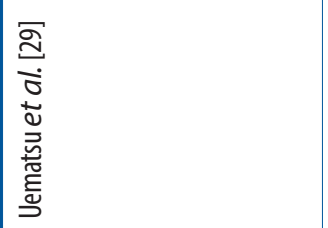 & 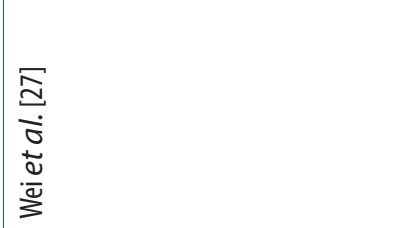 & 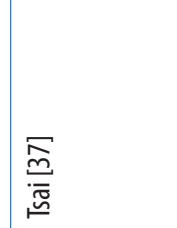 & 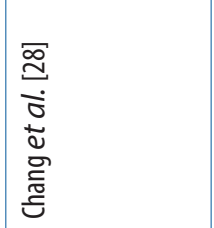 & 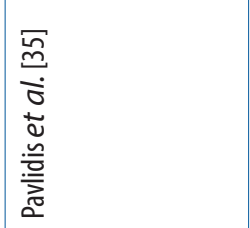 & 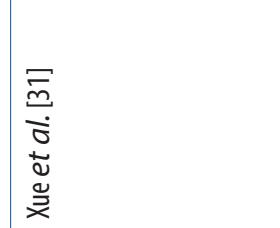 \\
\hline
\end{tabular}



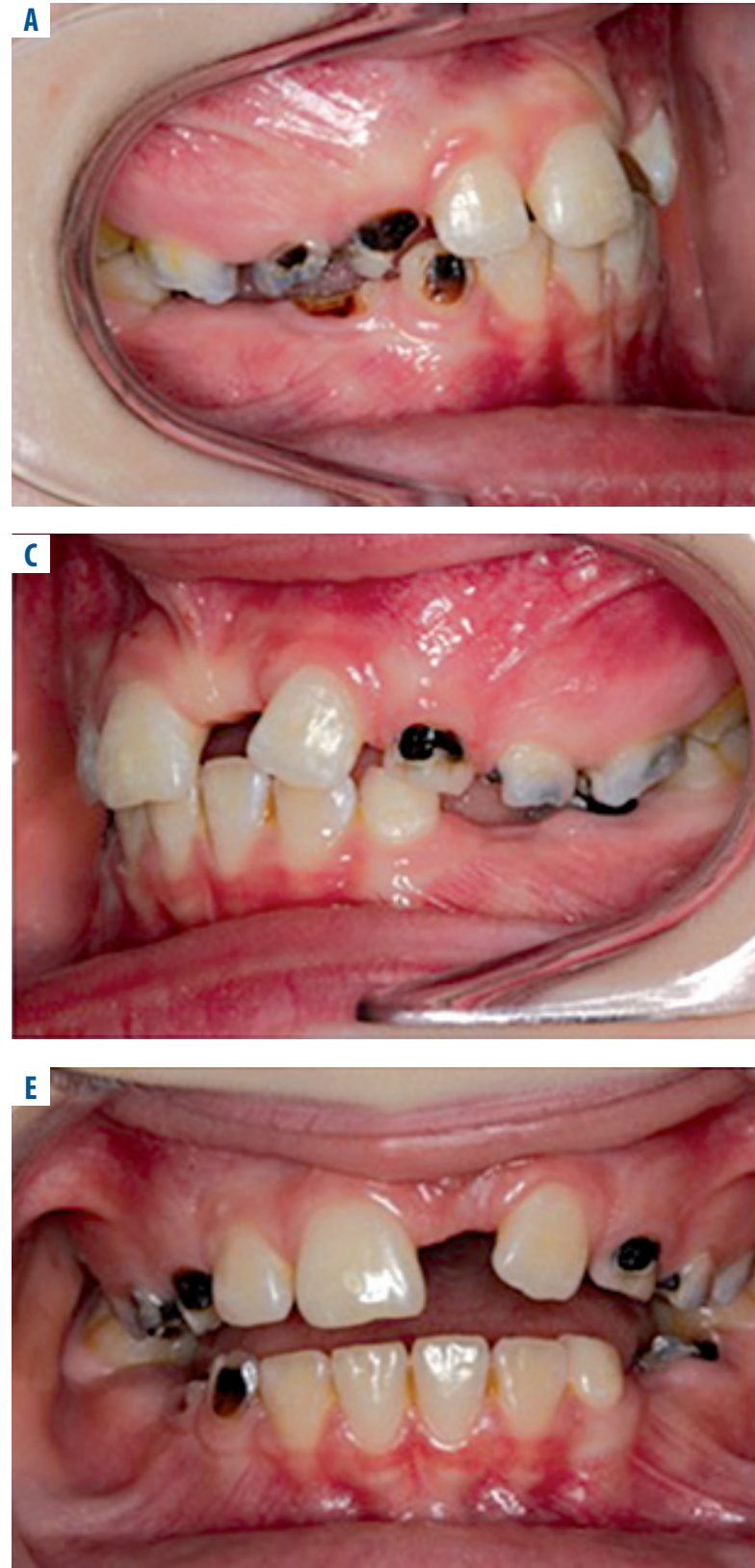

FIGURE 1. Intraoral photographs prior to treatment

\section{MATERIAL AND METHODS}

The literature review was carried out using the medical databases PubMed and Scopus. The search was carried out by entering the following keywords: dilaceration, impacted tooth, impacted maxillary central incisors. Non-systematic reviews of the literature were excluded from the analysis. Works describing the problem of impacted teeth with dilaceration in terms of etiology, frequency of occurrence, diagnostics and methods of treatment were included in order to systematize modern knowledge about the subject of impacted upper central incisors with dilaceration.
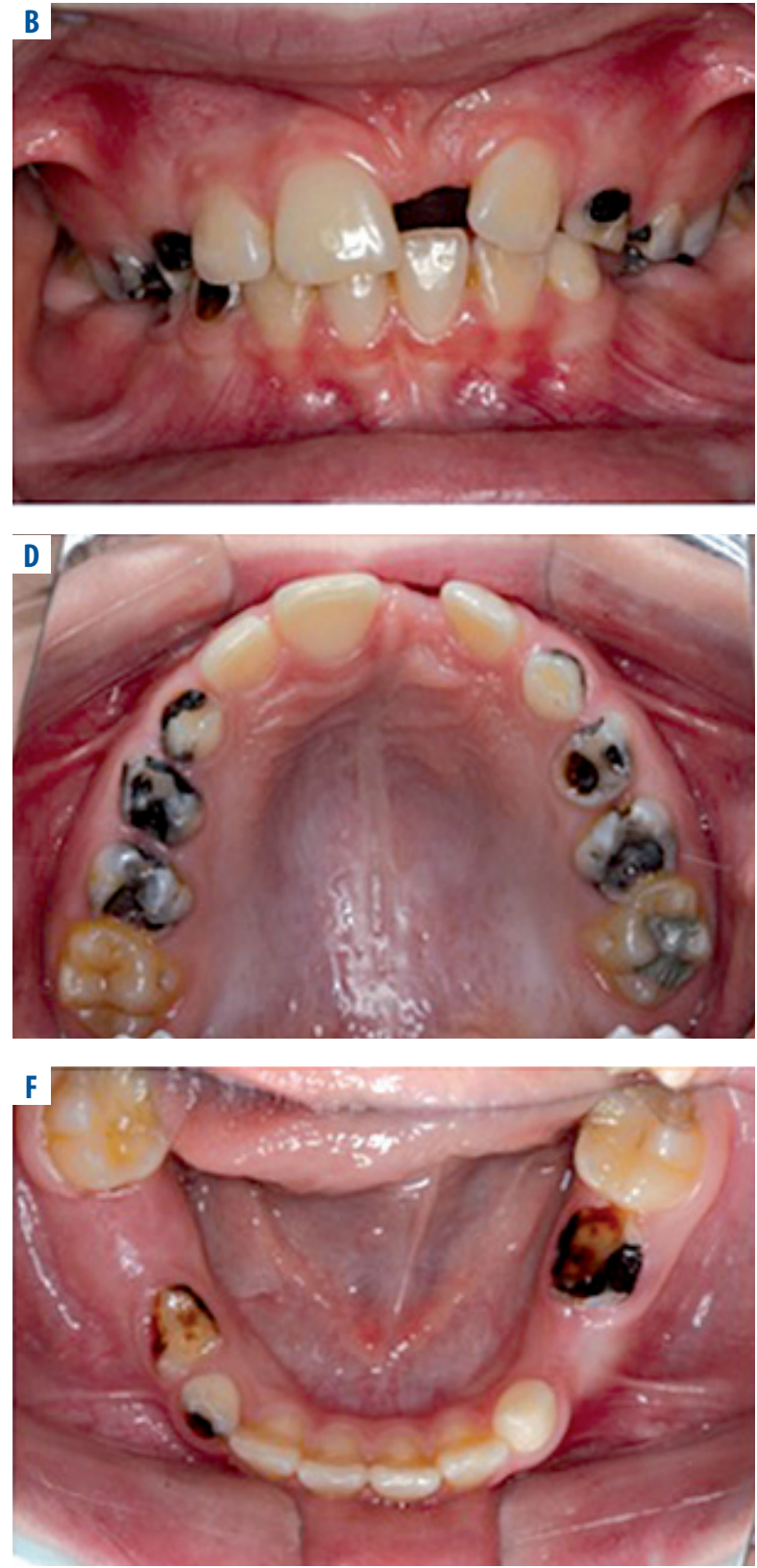

\section{RESULTS}

A total of 706 results published until 2018 were obtained, mainly in English. Twenty-nine articles corresponding to the objectives of the study were included in the review. Among them were original papers, metaanalyses and case reports. Table 1 lists found publications.

The factors influencing the prognosis of orthodontic extrusion of the impacted tooth with dilaceration include patient's age, the position of the impacted tooth in the bone, the degree of development of the root, degree of crown-root curvature, the amount of available space in the arch and the length of the tooth [31]. A better prognosis is shown by teeth with a more obtuse angle of crown-root 


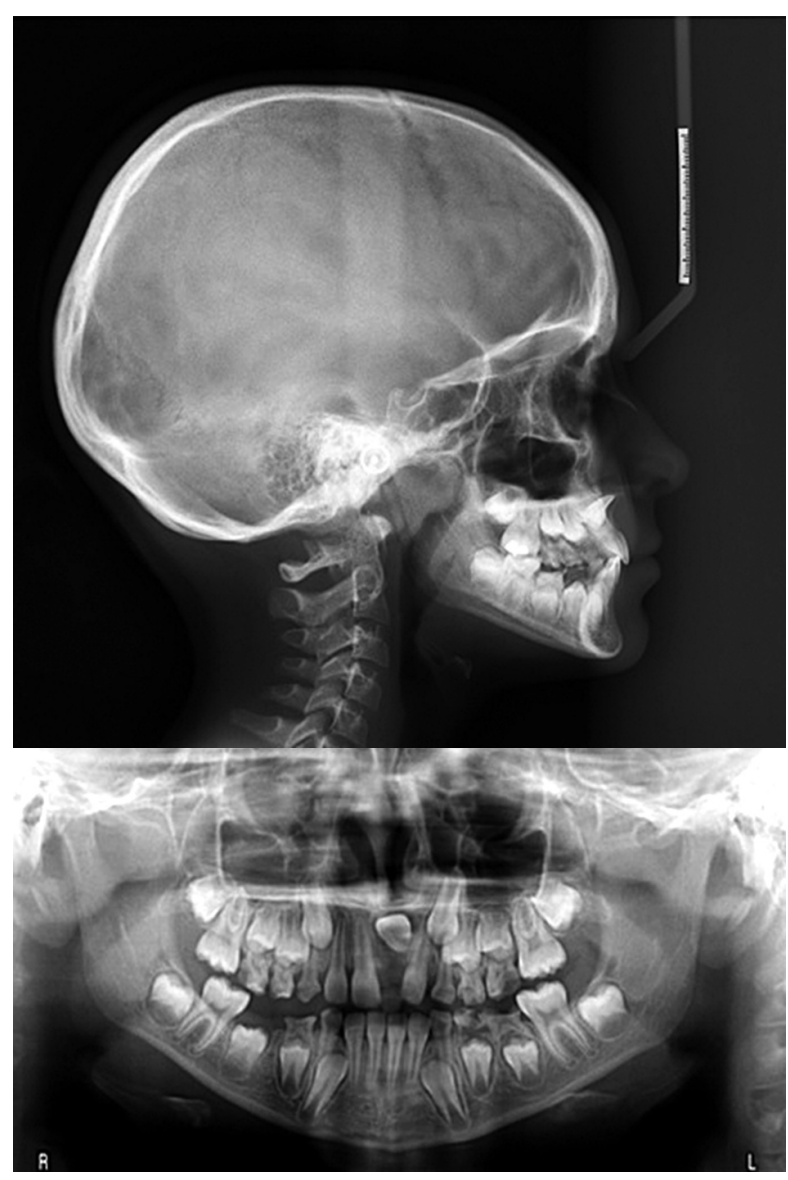

FIGURE 2. Radiological documentation prior to treatment

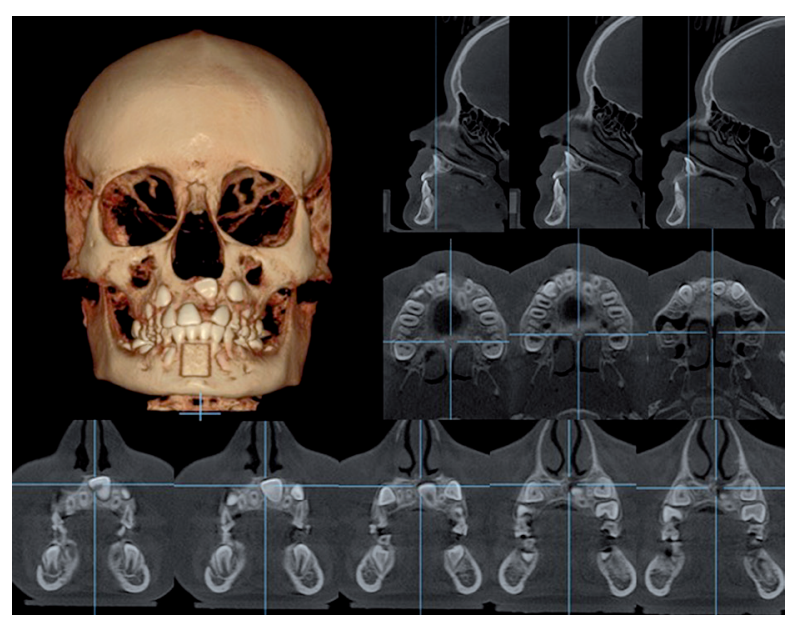

FIGURE 3. CBCT image prior to treatment

angulation, a low position in relation to the alveolar process and with uncompleted root development $[24,26,27]$.

The treatment of an impacted tooth with dilaceration involves the surgical unveiling of a tooth with an orthodontic extrusion to the arch. The alternative procedure is the surgical removal of the tooth followed by prosthetic or implant-prosthetic restoration, orthodontic closure of the removed tooth space or replantation of the tooth $[3,4,30,32]$. The majority of patients reporting for an impacted incisor are children; therefore all prosthetic solutions can only be temporary until growth is completed. The extraction of an impacted tooth in such patients will result in the loss of the bone, which affects the possibility of future prosthetic or implant-prosthetic restoration $[4,32]$. The method of choice is orthodontic extrusion of the tooth to the arch. The resulting benefits include, but are not limited to, the behavior of the tooth structure, the stimulation of alveolar bone formation, and the satisfactory aesthetics of the extruded tooth. Possible failure of such a procedure may be caused by ankylosis, rupture of ligaments, external resorption of the root, or puncture of the root through the alveolar ridge after tooth splitting, which may lead to tooth pulp necrosis, necessitating endodontic treatment and apicoectomy [25-28]. The natural tendency of the teeth is their migration and slope towards the gap after the removed or missing tooth, which results in a reduction or total lack of space in the arch for the missing tooth [1]. This situation enforces the implementation of orthodontic procedures aimed at restoring the space for a detained tooth before starting to bring it to the arch. Reconstruction of the space in the arch can be carried out by means of a removable appliance with springs for the distancing of teeth adjacent to the gap or by means of a fixed appliance $[3,25,27,28,30,32]$.

The method of surgical exposure of an impacted tooth affects the periodontal condition after the tooth has been extruded into the arch. There are two basic techniques of surgical uncovering of impacted teeth: the open method is called the window method and the closed method is called the tunnel technique. The window method consists of the radical removal of both the bone and soft tissues covering the crown of the unerupted tooth [3]. The disadvantage of an open eruption is the poor aesthetic appearance of the gum after the tooth has been inserted into the arch, manifesting itself in the unsuitable width of the attached gingiva [3, 33]. In the tunnel technique, the surgical procedure involves the surgical unveiling of an impacted tooth with intraoperative bonding of the orthodontic bracket and then covering the tooth with the mucoperiosteal flap. Many authors emphasize that this direction of extruding the tooth to the arch imitates the physiological process of tooth eruption. This technique is recognized as safe for the periodontium, providing the right amount of attached gingiva and proper formation of periodontium and meets the requirements of aesthetics [3, 25, 34, 35]. Soroka-Letkiewicz [35] showed that the surgical closed technique of uncovering impacted teeth allows one to obtain clinically unnoticeable differences, with an average size of $0.3 \mathrm{~mm}$ between the length of clinical crowns of imported teeth and unilateral teeth. Shi [34] obtained similar results. He investigated the influence of surgical closed technique on the incisors of the maxilla during orthodontic extrusion. After the procedure, the contour 

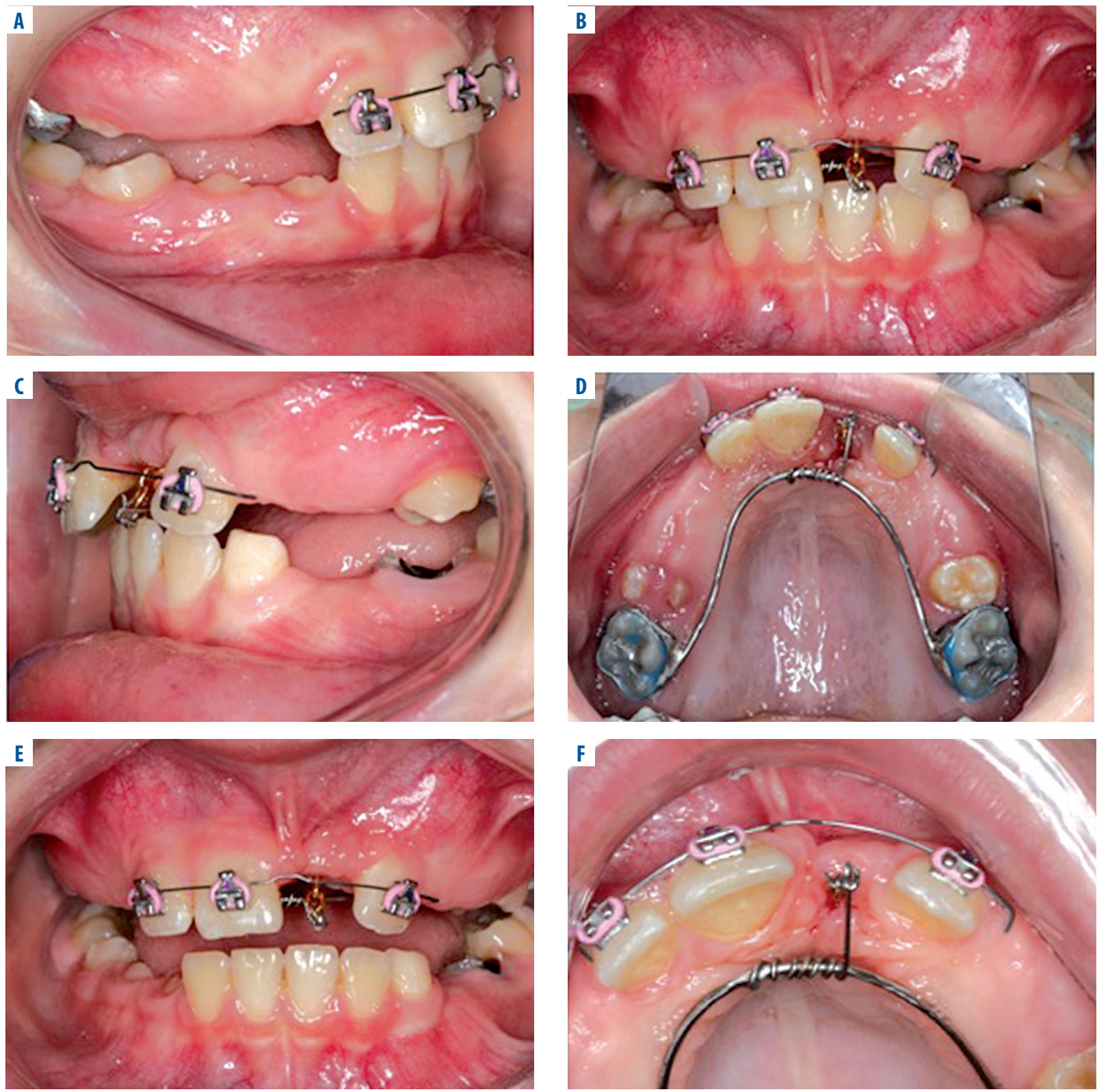

FIGURE 4. Intraoral photographs during treatment, the extrusion lever

of the gingival margin of the extruded incisor was consistent with the unilateral incisor, the position of the gum margin in $68 \%$ of extruded incisors was the same as in the case of the unilateral incisors of the opposing side, while the remaining $32 \%$ were more apical. In the 5 -year follow-up of the group of 10 patients with an impacted upper central incisor, half of whom underwent the surgical closed technique procedure of tooth uncovering and the other half underwent the closed method, Farronato [36] observed no statistically significant difference in periodontal tissue measurements (probing depth, clinical level of the attachment and gingival recessions) to the teeth naturally erupted. Periodontal procedures on the periodontium of the extruded tooth may contribute to increasing the width of keratinized gingiva and improving the aesthetics [25]. Dilaceration of the tooth complicates the process of tooth extrusion and often requires multiple surgical interventions to correct the direction of extrusion through changing the position of the orthodontic bracket $[24,26,28,30]$.

The time of tooth extrusion depends, similarly to factors affecting the prognosis of treatment success, on the position of the tooth in the bone [31], the stage of root development, and the degree of dilaceration. Studies conducted by Shi [34] on a group of 50 patients aged 6.4 to 10.4 years with an impacted maxillary central incisor with uncompleted root development, in which teeth were orthodontically extruded with surgical tooth exposure with the closed method, showed that the average time of bringing the tooth to the arch from the moment 

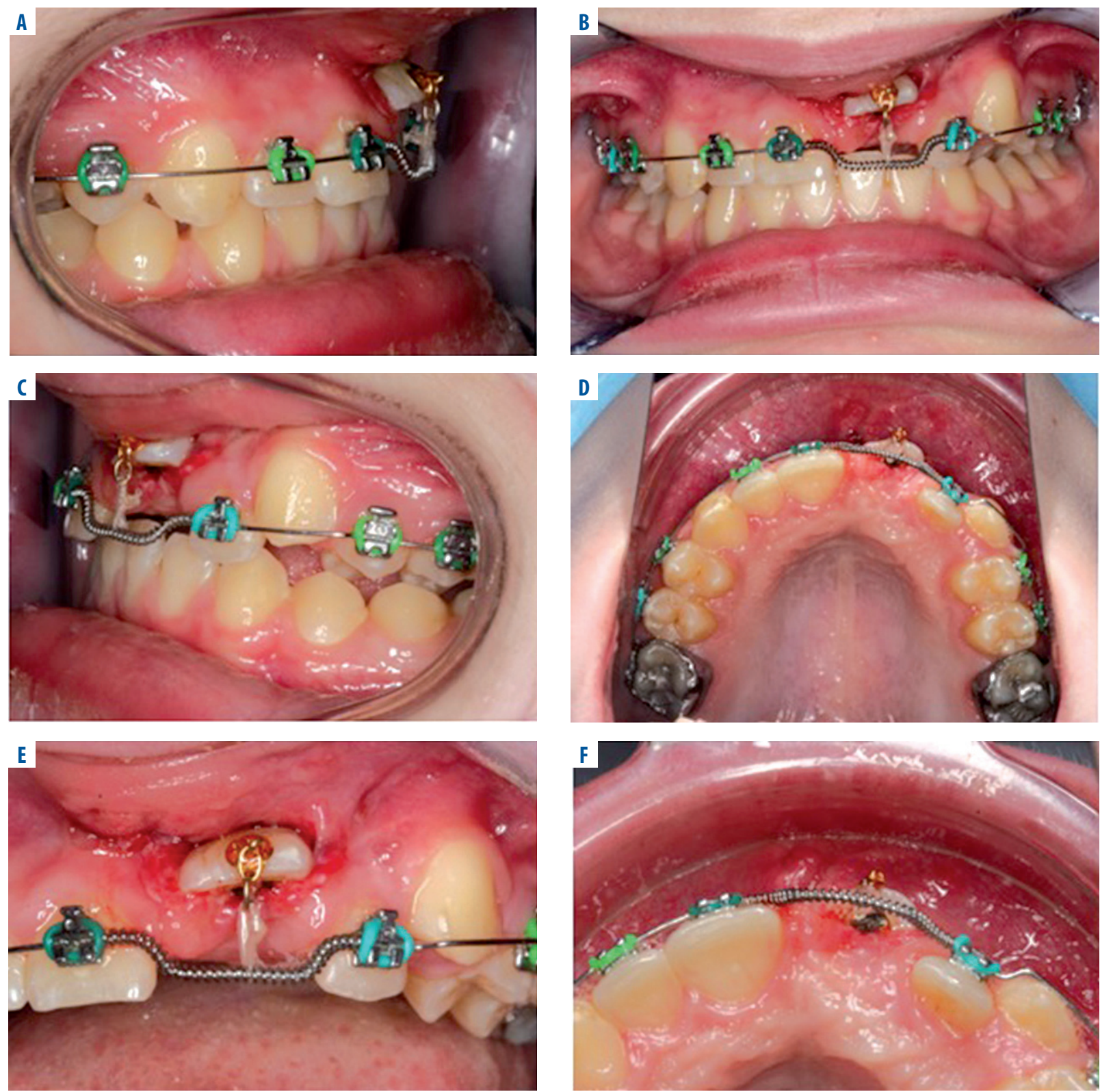

FIGURE 5. Intraoral photographs during treatment, after changing the position of the orthodontic bracket from lingual to vestibular surface of tooth 21

of bonding the hook for an impacted tooth was on average 11 months and was extended by 1 to 3 months if it was necessary to open the space in the arch for the impacted tooth. Chaushu [4] in the analysis of treatment of 60 patients with 64 impacted maxillary central incisors found an average time of orthodontic extrusion of $21.6 \pm 8.7$ months, with 5 of 6 treatment failures related to dilacerated teeth. Dilaceration was associated with a longer time of extrusion and in patients with late or mixed permanent teeth extended the final stage of treatment [4]. In the Lygidakis [31] study, the average duration of treatment in a group of 46 people aged 7.3-12 years (mean $=9.44 \pm 1.36)$ with 54 impacted central maxillary incisors was 5 to 21 months (mean $9.88 \pm 3.10$ ), while without preoperative orthodontics or without remov- ing obstacles in the way of extrusion, the time of treatment was 12 to 18 months (mean $15 \pm 2.12$ ) and 17 to 30 months (mean $23.73 \pm 5.14$ ). The time required for full eruption depended on the inclination of the tooth, the height at which the impacted tooth was located and the age of the patient. In addition, the lack of orthodontic restoration of the space before surgery significantly extended the duration of treatment. Another study, conducted by Bhikoo [37], examined 35 patients aged $8.36 \pm 1.36$ years with an impacted upper central incisor to assess the effect of factors such as the patient's age, tooth crown height, tooth axis rotation, tooth rotation, size of dilaceration or tooth length for the time of orthodontic tooth extraction to the arch. The average duration of treatment in this study was $11.28 \pm 3.08$ months and 

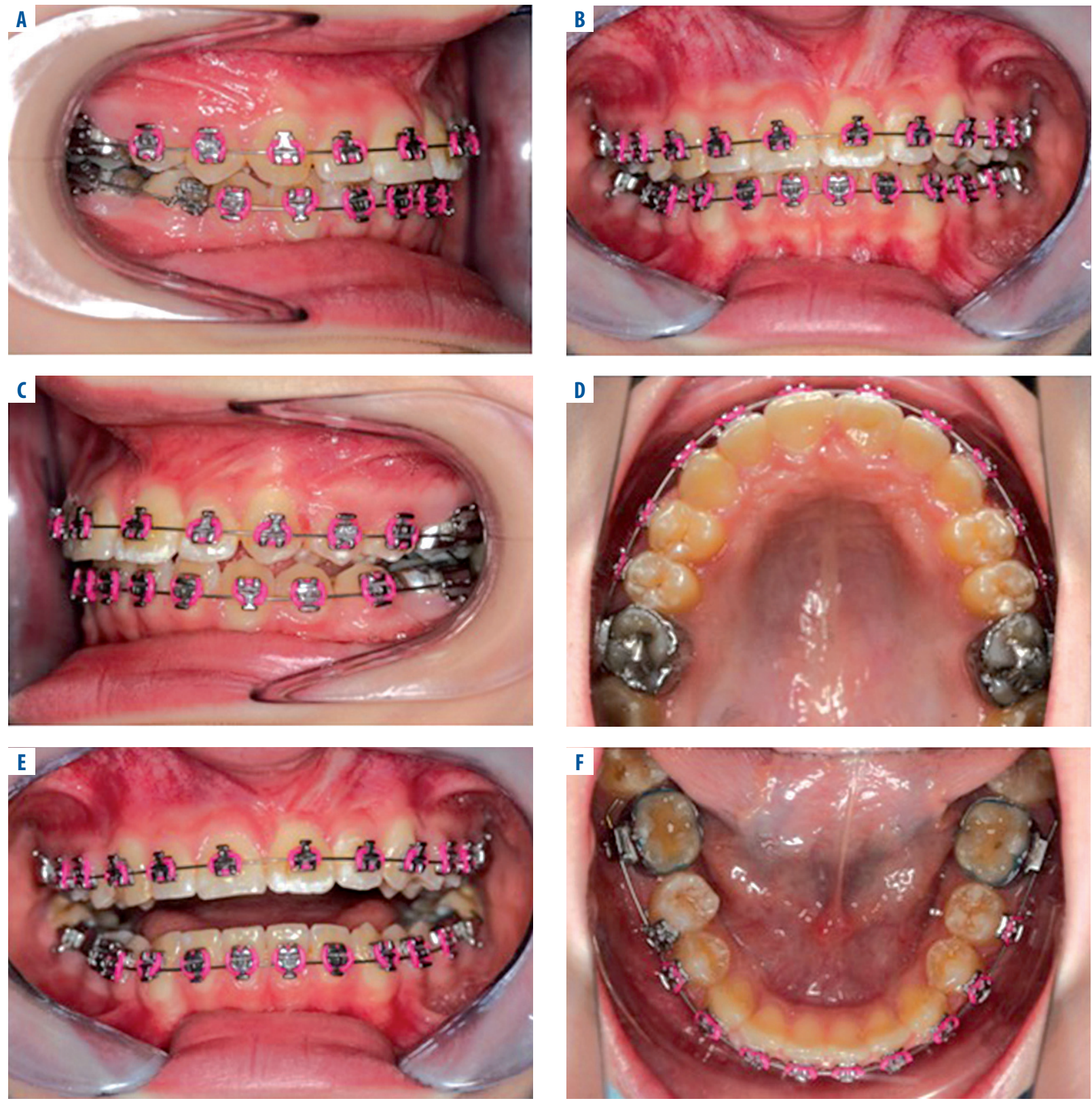

FIGURE 6. Intraoral photographs after extrusion of tooth 21

the factors with the greatest impact on the elongation of treatment time were patient age, tooth crown height, dilaceration degree and tooth length.

The problem of impacted teeth with diagnosed dilaceration is illustrated by the description of the orthodontic and surgical treatment of the case.

A patient aged 8 years and 9 months was qualified for orthodontic treatment due to malocclusion complicated by delayed tooth eruption of tooth 21 . Due to inadequate oral hygiene and numerous carious cavities, the patient was referred to the general dentist prior to the implementation of orthodontic treatment (Figure 1).

In the interview, there was no injury to the anterior deciduous teeth during early childhood, or the occurrence of systemic diseases.
In the extraoral examination, the patient's profile was defined as a straight, preserved facial symmetry and the correct vertical dimension of the maxillary segment. The profile analysis determined a slight increase in facial angle and facial contour angle, correct position of the upper lip, decreased nasolabial angle and slight lower lip extension. In the intraoral examination, it was found that the center line of the teeth was displaced to the left by $1.5 \mathrm{~mm}$. Analyzing the lines of measures relative to the facial symmetry line, it was found that the line in the rest position of the mandible was normal, and because tooth 21 had been impacted, the midline arch of the upper arch had been shifted by $1.5 \mathrm{~mm}$ towards the left. Intra-oral diagnosis was angle class I, horizontal bite of $3 \mathrm{~mm}$ and vertical bite $3 \mathrm{~mm}$. Occlusal maturation 


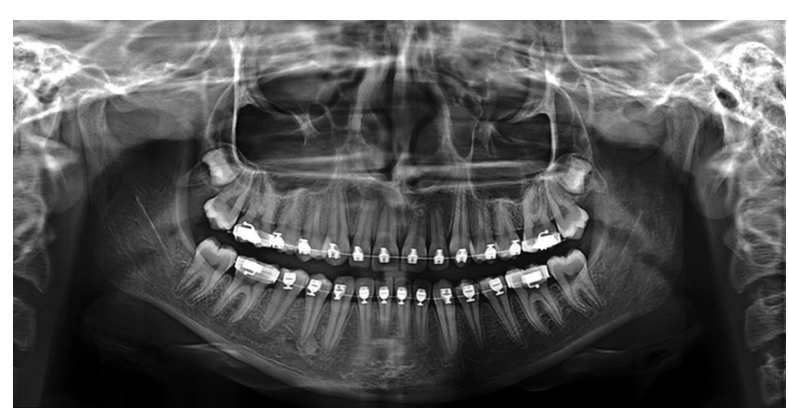

FIGURE 7. OPG after the extrusion of tooth 21

was determined at the level of DS1 M1 according to Bjork, Krebs and Solow [38].

The orthopantomogram (OPG) assessment showed the presence of impacted tooth 21 and all permanent teeth with the exception of tooth buds 18, 28, 38 and 48. The cone beam computed tomography (CBCT) image revealed the presence of a left upper impacted tooth. The tooth was located horizontally in the region of the anterior nasal spine, with a sigmoid root with a curved apex towards the base of the maxilla. The development of the root of the impacted tooth was completed (Figures 2 and 3). The cephalometric analysis was carried out according to the rationalized cephalometry of the Kracovia System [39] in the Facad computer program. On the basis of the analysis of the photograph, the presence of an anterior sagittal relation of the bone base was found with the maxilla retrognation and mandible located orthognathically, the maxillary incisors were protruded in compensation while the mandibular teeth closed to the normal position with a reduced interincisal angle. In the vertical dimension, the angle of the jaw bases was slightly increased. Mandibular morphology, as well as the numerical analysis, indicated a posterior rotational growth pattern.

Based on the collected data, interdisciplinary orthodontic and surgical treatment was planned to introduce the impacted tooth 21 into the dental arch. The treatment plan included reconstructing the space for the impacted tooth followed by surgical exposure of the tooth and bonding the orthodontic bracket to the palatal side of the tooth crown and orthodontic extrusion. Due to numerous missing teeth, the treatment was started with the use of the upper plate, which in the next phase was replaced with a segmented fixed appliance in the Cannon Ultra System and a circular palatal arch with a soldered extrusion lever. Five months after the orthodontic preparation, a surgical exposure of the impacted tooth was performed with the attachment of the abutment on the palatal side of tooth 21, in the form of a gold chain (Figure 4 ). The chain on tooth 21 was initially connected to the extrusion lever of the trans-palatal arch. After changing from a segmental to a full fixed appliance, the chain was tied with a flexible thread to the arch of the Cannon US appliance. The extrusion system was activated at each visit by cutting the mesh of the chain and re-linking to the arch with a new elastic thread. After 13 months of treatment, it was decided to bond the orthodontic bracket on the extruded tooth to the vestibular surface in order to improve the direction of its eruption to the arch and derotation (Figure 5) which was associated with the second surgery. Further activation followed the above-described pattern. After 32 months of orthodontic treatment, the impacted tooth with dilaceration was attached to the dental arch and reached the occlusal plane. After the tooth was brought to the arch, the tooth vitality test was performed with ethyl chloride and a vertical tooth test; the correct reaction was found in both tests. Palpation in the vestibule of the oral cavity revealed the presence of the root tip of tooth 21 . The correct position of tooth 21 in the dental arch was obtained and acceptable aesthetics were achieved. On the orthopantomographic image, after the impacted tooth had been brought into the arch, the root shortening of tooth 21 was visible due to the bend of its apex in the peripheral direction (Figures 6 and 7).

\section{CONCLUSIONS}

Dilaceration of permanent teeth is a relatively rare phenomenon. Patients with diagnosed impacted tooth with dilaceration require detailed diagnostics supported by radiological examinations in order to plan orthodontic treatment. Implementation of comprehensive orthodontic and surgical treatment at an early stage of tooth development gives the best prognosis to introduce a tooth with dilaceration to the dental arch. Treatment of impacted upper central incisors with dilaceration requires an interdisciplinary approach based on close cooperation between the orthodontist, the surgeon and the periodontist as well as good cooperation on the part of the patient. The treatment of choice is an orthodontic attempt to bring the unerupted tooth to the arch. Extrusion of an impacted tooth in the anterior region contributes to a significant improvement in the aesthetics of the teeth, which is of particular importance for patients in adolescence and contributes to the improvement of the quality of life.

\section{CONFLICT OF INTEREST}

The authors declare no potential conflicts of interest with respect to the research, authorship, and/or publication of this article.

\section{References}

\footnotetext{
1. Tan C, Ekambaram M, Yiu CKY. Prevalence, characteristic features and complications associated with the occurrence of unerupted permanent incisors. PLoS One 2018; 13: e0199501.

2. Betts A, Camilleri GE. A review of 47 cases of unerupted maxillary incisors. Int J Paediatr Dent 1999; 9: 285-292.
} 
3. Pinho T, Neves $M$, Alves C. Impacted maxillary central incisor: surgical exposure and orthodontic treatment. Am J Orthod Dentofacial Orthop 2011; 140: 256-265.

4. Chaushu S, Becker T, Becker A. Impacted central incisors: factors affecting prognosis and treatment duration. Am J Orthod Dentofacial Orthop 2015; 147: 355-362.

5. Stewart DJ. Dilacerate unerupted maxillary central incisors. $\mathrm{Br}$ Dent J 1978; 145: 229-233.

6. Topouzelis N, Tsaousoglou P, Pisoka V, Zouloumis L. Dilaceration of maxillary central incisor: a literature review. Dent Traumatol 2010; 26: 427-433.

7. Hamasha AA, Al-Khateeb T, Darwazeh A. Prevalence of dilaceration in Jordanian adults. Int Endod J 2002; 35: 910-912.

8. Colak H, Bayraktar Y, Hamidi MM, et al. Prevalence of root dilacerations in Central Anatolian Turkish dental patients. West Indian Med J 2012; 61: 635-639.

9. Malcić A, Jukić S, Brzović V, et al. Prevalence of root dilaceration in adult dental patients in Croatia. Oral Surg Oral Med Oral Pathol Oral Radiol Endod 2006; 102: 104-109.

10. Miloglu O, Cakici F, Caglayan F, et al. The prevalence of root dilacerations in a Turkish population. Med Oral Patol Oral Cir Bucal 2010; 15: 441-444.

11. Silva BF, Costa LED, Beltrão RV, et al. Prevalence assessment of root dilaceration in permanent incisors. Dental Press J Orthod 2012; 17: 97-102.

12. Nabavizadeh M, Sedigh Shamsi M, Moazami F, Abbaszadegan A. Prevalence of root dilaceration in adult patients referred to Shiraz dental school (2005-2010). J Dent (Shiraz) 2013; 14: 160-164.

13. Guttal KS, Naikmasur VG, Bhargava P, Bathi RJ. Frequency of developmental dental anomalies in the Indian population. Eur J Dent 2010; 4: 263-269.

14. Ledesma-Montes C, Garcés-Ortíz M, Salcido-García JF, HernándezFlores F. Study on frequency of dental developmental alterations in a Mexican school-based population. Med Oral Patol Oral Cir Bucal 2016; 21: 316-320.

15. Goncalves-Filho AJ, Moda LB, Oliveira RP, et al. Prevalence of dental anomalies on panoramic radiographs in a population of the state of Pará, Brazil. Indian J Dent Res 2014; 25: 648-652.

16. Ezoddini AF, Sheikhha MH, Ahmadi H. Prevalence of dental developmental anomalies: a radiographic study. Community Dent Health 2007; 24: 140-144.

17. Bilge NH, Yeşiltepe S, Törenek Ağırman K, et al. Investigation of prevalence of dental anomalies by using digital panoramic radiographs. Folia Morphol 2018; 77: 323-328.

18. Afify AR, Zawawi KH. The prevalence of dental anomalies in the Western region of Saudi Arabia. ISRN Dent 2012; 2012 : 837270 .

19. Patil S, Doni B, Kaswan S, Rahman F. Prevalence of dental anomalies in Indian population. J Clin Exp Dent 2013; 5: 183-186.

20. Goutham B, Bhuyan L, Chinnannavar SN, et al. Prevalence of dental anomalies in Odisha population: a panoramic radiographic study. J Contemp Dent Pract 2017; 18: 549-553.

21. Saberi EA, Ebrahimipour S. Evaluation of developmental dental anomalies in digital panoramic radiographs in Southeast Iranian population. J Int Soc Prev Community Dent 2016; 6: 291-295.

22. Shokri A, Poorolajal J, Khajeh S, et al. Prevalence of dental anomalies among 7- to 35-year-old people in Hamadan, Iran in 2012-2013 as observed using panoramic radiographs. Imaging Sci Dent 2014 44: 7-13.

23. Udoye CI, Jafarzadeh H. Dilaceration among Nigerians: prevalence, distribution, and its relationship with trauma. Dent Traumatol 2009; 25: 439-441.

24. Walia PS, Rohilla AK, Choudhary S, Kaur R. Review of dilaceration of maxillary central incisor: a mutidisciplinary challenge. In J Clin Pediatr Dent 2016; 9: 90-98.

25. Wei YJ, Lin YC, Kaung SS, et al. Esthetic periodontal surgery for impacted dilacerated maxillary central incisors. Am J Orthod Dentofacial Orthop 2012; 142: 546-551.
26. Chang NY, Park JH, Kim SC, et al. Forced eruption of impacted maxillary central incisors with severely dilacerated roots. Am J Orthod Dentofacial Orthop 2016; 150: 692-702.

27. Uematsu S, Uematsu T, Furusawa K, et al. Orthodontic treatment of an impacted dilacerated maxillary central incisor combined with surgical exposure and apicoectomy. Angle Orthod 2004; 74: 132 136

28. Xue JJ, Ye NS, Li JY, Lai WL. Management of an impacted maxillary central incisor with dilacerated root. Saudi Med J 2013; 34 1073-1079.

29. Sun H, Wang Y, Sun C, et al. Root morphology and development of labial inversely impacted maxillary central incisors in the mixed dentition: a retrospective cone-beam computed tomography study. Am J Orthod Dentofacial Orthop 2014; 146: 709-716.

30. Pavlidis D, Daratsianos N, Jäger A. Treatment of an impacted dilacerated maxillary central incisor. Am J Orthod Dentofacial Orthop 2011; 139: 378-387.

31. Lygidakis NN, Chatzidimitriou K, Theologie-Lygidakis N, Lygidakis NA. Evaluation of a treatment protocol for unerupted maxillary central incisors: retrospective clinical study of 46 children. Eur Arch Paediatr Dent 2015; 16: 153-164.

32. Tsai TP. Surgical repositioning of an impacted dilacerated incisor in mixed dentition. J Am Dent Assoc 2002; 133: 61-66.

33. Becker A. Early treatment for impacted maxillary incisors. Am J Orthod Dentofacial Orthop 2002; 121: 586-587.

34. Shi XR, Hu Z, Wang XZ, et al. Evaluation of the effect of the closed-eruption technique on impacted immature maxillary incisors. Chin J Dent Res 2015; 18: 111-115.

35. Soroka-Letkiewicz B, Zienkiewicz J, Dijakiewicz M. Wykorzystanie metody „zamkniętego wyrzynania” w chirurgiczno-ortodontycznym leczeniu niewyrzniętych lub zatrzymanych zębów. Ann Acad Med Gedan 2005; 35: 97-108.

36. Farronato G, Giannini L, Galbiati G, Maspero C. A 5-year longitudinal study of survival rate and periodontal parameter changes at sites of dilacerated maxillary central incisors. Prog Orthod 2014, 15: 3 .

37. Bhikoo C, Xu J, Sun H, et al. Factors affecting treatment duration of labial inversely impacted maxillary central incisors. Am J Orthod Dentofacial Orthop 2018; 153: 708-715.

38. Bjork A, Krebs A, Solow B. A method of epidemiological registration of malocclusion. Acta Odonto Scand 1964; 22: 27-41.

39. Williams S, Loster BW. Zracjonalizowana Cefalometria Systemu Kracovia (CSK). J Stoma 2012; 65: 525-542. 